\begin{tabular}{ccc|} 
PEDIOMATERNAL \\
NURSING JOURNAL \\
Vol. 7, No. 2, September 2021 \\
Journal Homepage: https://e-journal.unair.ac.id/PMNJ/ \\
http://dx.doi.org/10.20473/pmnj.v7i2.27508
\end{tabular}

Review

\title{
Factors Affecting the Implementation of Developmental Care in the Care of Premature Babies in NICU Nurses: A Systematic Review
}

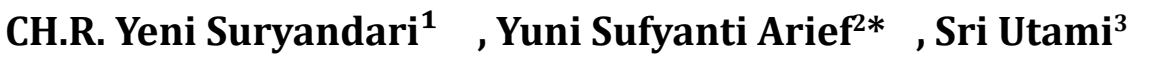 \\ ${ }^{1}$ Master in Nursing Study Program, Faculty of Nursing, Universitas Airlangga, Surabaya, Indonesia \\ ${ }^{2}$ Department of Fundamental Nursing, Faculty of Nursing, Universitas Airlangga, Surabaya, Indonesia \\ ${ }^{3}$ Department of Midwifery, Poltekkes Kemenkes Surabaya, Surabaya, Indonesia
}

\section{ARTICLE HISTORY}

Received : June 14, 2021

Revised : July 13, 2021

Accepted : July 21, 2021

Published : September 1, 2021

\section{KEYWORDS}

preterm infant; developmental care; nursing care; NICU

\section{CORRESPONDING AUTHOR}

*Yuni Sufyanti Arief

yuni_sa@fkp.unair.ac.id Department of Fundamental Nursing, Faculty of Nursing, Universitas Airlangga, Surabaya, Indonesia

Cite this as:

\section{INTRODUCTION}

Developmental care-based preterm care management that aims to protect the nervous system and reduce harmful effects has evolved over the last few decades. Due to advances in science and technology, babies born at 23

\begin{abstract}
Introduction: Developmental care-based preterm infant care management that aims to protect the neurological system and reduce adverse effects has developed over the last few decades. The study aimed to explore the factors that influence the implementation of developmental care among NICU nurses.

Methods: The study was systematically identified by searching an electronic database using keywords "preterm infant" AND "developmental care" AND "nursing care" AND "NICU" and consisted of 2130 articles from Scopus, Science Direct, goggle scholar, ProQuest, and PubMed. Data sources were limited to articles published from 2015 to 2020 and those published in English. Thirteen studies were included in this systematic review. The inclusion criteria were nurses caring for preterm infants at the NICU, a cross-sectional descriptive study of quantitative or qualitative research.

Results: Thirteen articles indicated that the developmental care implementation among NICU nurses was influenced by positive, perceptions knowledge, attitudes of developmental care. Professional skills are the most substantial impact on developmental care implementation to improve nurses' nursing development and increase the competence of individual nurses.

Conclusion: Positive perceptions about organizational support and developmental care are needed. The training care program also benefits to nurses by increase self-confidence in implementing developmental care for premature babies.
\end{abstract}

Suryandari, CH. R, Y., Arief, Y, S., \& Utami, S. (2021). Factors Affecting the Implementation of Developmental Care in the Care of Premature Babies in NICU Nurses: A Systematic Review. Pediomaternal Nurs. J., 7(2), 77-83. Doi: http://dx.doi.org/10.20473/pmnj.v7i2.27508 
Complications of preterm birth cause 15 million babies to be born prematurely and about 1 million children die (WHO, 2012). Indonesia is included in the top 10 of 184 countries with a high preterm birth rate (15.5 premature births per 100 births) in 2012 (WHO, 2012). Neurodevelopmental care is a family and infant care philosophy and framework (Lynn Lingen, 2019). The goals of developmental care are to reduce stress in premature infants, improve neurological, cognitive, and behavioral functions, and prevent neurodevelopmental problems (Mosqueda-Peña et al., 2016). Even though it has been implemented in several hospitals, many nurses have not carried out developmental care due to a lack of confidence. Besides that, previous study proved that skinto-skin contact is the primary treatment of developmental care (Deng et al., 2018). It was still found that the level of knowledge, attitudes, and practices of neonatal nurses about skin-to-skin contact was still relatively low. Developmental care is indispensable in the care of premature babies, taking into account the effects of preterm birth. The new environment in the intensive care unit causes stress in infants which adversely affects the quality of life of premature infants and their families (Macho, 2018). Stress caused by a new environment can affect brain development, causing neurodevelopmental disorders in premature babies (Altimier et al., 2015), which results in the risk of permanent physical, motor, cognitive impairment (Su et al., 2016).

The role of the nurse is very important for the success of treatment for the neurodevelopment of premature infants (Park \& Kim, 2019). Meanwhile, research (Mahl et al., 2015) reported that professional ability had the most decisive impact on developmental care practice in NICU nurses. high professional ability, a strong sense of optimism and motivation have a positive impact on the professional performance of nurses. The positives about developmental care are the reduction in developmental disorders and psychomotor delays in a two-year-old child with a history of 32 weeks' gestation (KiechlKohlendorfer et al., 2015). The purpose of this study was to explore the factors that influence the implementation of developmental care among NICU nurses.

\section{METHOD}

\section{Database}

The sources of the articles used in this systematic review were research databases such as Scopus, ProQuest, Pubmed, Google Scholar, and Science Direct. Additional articles were selected through citations to the papers included in this systematic review.

\section{Keywords and Search Terms}

The search for articles in selected databases was carried out with the help of Boolean Operators with a combination of keywords and search terms as follows: "preterm infant" OR "preterm babies" AND "developmental care" OR NIDCAP AND nursing OR "nursing care" AND NICU OR "neonatal intensive".

\section{Article Selection}

Systematic reviews were written based on the PRISMA (Preferred Reporting Items for Systematic Reviews and Meta-Analyzes) guidelines. We limit the period of search literature from 2015 to 2020: original articles in English, sources from journals, nurses' knowledge, skills, attitudes, perceptions, practices of developmental care, available in full text. Only articles that met the following inclusion criteria were included in this systematic review, namely participants or the sample. The population was limited to nurses caring for premature babies (gestational age $<37$ weeks--Intervention or implementation of development care by nurses. Comparisons or research contexts carried out in hospitals in both developing, developed, and emerging countries. Results and objectives was to explore the factors/predictors/determinants and contributors to the nurses' behavior in implementing developmental care for caring for premature babies. The exclusion criteria were secondary data, review articles, conference articles and did not explain the factors that influence the implementation of developmental care among NICU nurses (Figure 1).

\section{Data Extraction}

All titles were filtered from the source database to exclude irrelevant studies. The systematic 


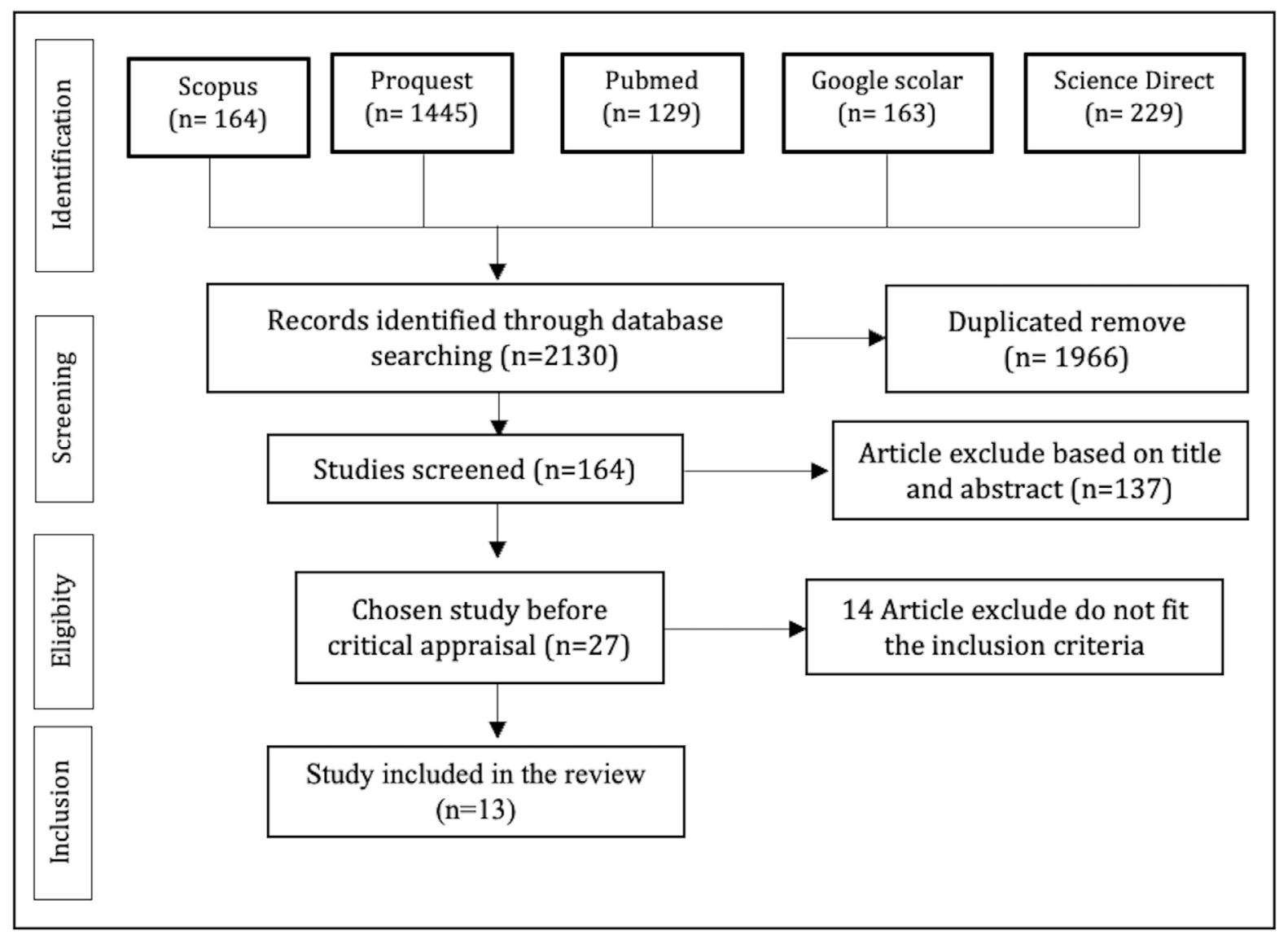

Figure 1. Articles Selection Process Using PRISMA

preferred reporting items for systematic reviews (the JBI Critical Appraisal) guidelines were used for design and results.

\section{RESULT}

\section{General Characteristics}

Based on the 13 articles analyzed (Table 1 ), the most common type of research was cross-sectional research with 7 articles and qualitative research with 1 article, mixedmethod 2 articles and Quasi-experiment 1 article, observation study 1, pilot study 1 . The most types of intervention are (training on NIDCAP, survey of developmental care practices, survey of knowledge, attitudes, perceptions of developmental care, interviews about the experience of caring for premature babies) with 7 articles.

Training and practice on developmental care positively impact the positive perceptions and efficacy of NICU nurses (Charafeddine et al., 2020). The qualitative results showed that the neonate nurse revealed that the importance of quality of life in premature infants with low birth weight (Green et al., 2017). Wee Care's NICU Neuroprotective Program is an integrated model of neonatal developmental care that incorporates best evidence-based practices into education and training resulting in better outcomes in the care of preterm and high-risk sick infants (Altimier et al., 2015).

\section{Intervention}

The types of intervention were educational interventions $(30,76 \%)$, monitoring the implementation of developmental care (15.3\%), surveys about knowledge, attitudes, perceptions, skills (46.15\%). There are several types of interventions, namely pain assessment, kangaroo mother care, lactation in premature babies (Deng et al., 2018), (Capolingua \& Gill, 2018), (Blatz et al., 2020). The NIDCAP training is linked to attitudes, perceptions, knowledge, practices for NICU nurses (Charafeddine et al., 2020; Baghlani et al., 2019). More specific details about each study are given in Table 2 . The main result measured in this study was the implementation of developmental care by nurses in practice 
Table 1. General Characteristics of Selected Studies (n=13).

\begin{tabular}{lll}
\hline Category & $\mathbf{n}$ & $\mathbf{\%}$ \\
\hline Year of Publishing & & 7.6 \\
2015 & 1 & 15.3 \\
2016 & 2 & 23.07 \\
2017 & 3 & 23.07 \\
2018 & 3 & 15.3 \\
2019 & 2 & 15.3 \\
2020 & 2 & 30.76 \\
Type of Intervention & & 15.3 \\
Training of developmental care & 4 & 46.15 \\
The practice of developmental care & 2 & 7.6 \\
Survey knowledge, attitude, perception, skill & 6 & \\
Interview & 1 & 53.84 \\
Type of Study & & 7.6 \\
Cross-sectional research & 7 & $1 ., 3$ \\
Pilot study & 1 & 7.6 \\
Mix Qualitative and Quantitative study & 2 & 7.6 \\
Prospective, quasi-experimental pre and post design & 1 & 7.6 \\
Observational study & 1 & 1 \\
Qualitative study & & \\
\hline
\end{tabular}

which is influenced by factors of knowledge, attitudes, perceptions, skills, training. Thirteen studies conducted a review show that training such as The Wee Care Neuroprotective NICU Program, Family-Centered Developmental Care can significantly improve nurses' knowledge, positive perceptions, attitudes, skills.

\section{DISCUSSION}

\section{Knowledge, Attitude, Perception}

It was reported that practices and attitudes towards pain assessment and management as components of developmental care were positive (Capolingua \& Gill, 2018). The level of education was identified as having an impact on knowledge so that nurses identify negative signals from babies due to pain and pain pathways (Capolingua \& Gill, 2018). In another study, after receiving NIDCAP training, most of the respondents had positive attitudes about NIDCAP implementation. Nurses and doctors think that the NIDCAP model improves the quality of the well-being of babies, the caregivers' relationships with parents, their working conditions (Charafeddine et al., 2020). A high level of knowledge will indicate that nurses obtain a better level of job satisfaction through the application of developmental care and show better performance, higher confidence in their professional role (Baghlani et al., 2019). Nursing perceptions of the action are also a factor influencing developmental care practice among NICU nurses. Nurses' perceptions can lead to better implementation of developmental care (Mosqueda-Peña et al., 2016).

\section{Training of Developmental Care}

The benefits of developmental care show that with training, good education and supportive leadership, it has been successful in applying neuroprotection to family knowledge to support developmental care (Altimier et al., 2015). Research results from (Konishi et al., 2017) demonstrated that participants' neonatal particular education program was found to experience changes in their perception of their role and differences in their interactions with peers.

\section{The Practice of Developmental Care}

This study shows that the professional skills of nurses have a significant effect on the practice of nursing care in the NICU room. Professional skills, a strong sense of optimism and motivation to work have a positive impact on the professional performance of NICU nurses (Park \& Kim, 2019). Barriers to developmental care practices were also found in family-centered care; this was due to a lack of knowledge regarding developmental care and 
Table 2. Summary of Selected Studies

\begin{tabular}{|c|c|c|c|}
\hline Years & Intervention & Design Study & Outcome \\
\hline 2020 & $\begin{array}{l}\text { NIDCAP is carried out in } 2 \text { phases based on } \\
\text { the theory of planned behavior. Phase one } \\
\text { from June } 2014 \text { to May } 2018 \text { and phase two } \\
\text { from June } 2018 \text { to February } 2019 \text {. }\end{array}$ & $\begin{array}{l}\text { A Cross-section- } \\
\text { al study }\end{array}$ & $\begin{array}{l}\text { Increasing attitude, perceived behavior, } \\
\text { intention, behavior in nurses. }\end{array}$ \\
\hline 2019 & $\begin{array}{l}\text { The research includes the characteristics } \\
\text { of the respondents, the nurse's work } \\
\text { environment, the nurse's perception of } \\
\text { developmental care, organizational culture, } \\
\text { work professionalism and the practice of } \\
\text { providing developmental care. }\end{array}$ & $\begin{array}{l}\text { A Cross-section- } \\
\text { al study }\end{array}$ & $\begin{array}{l}\text { Professional ability and organizational } \\
\text { culture with a task-oriented very } \\
\text { influence on baby care. Nurses with } \\
\text { educational background and training in } \\
\text { developmental care have no effect on care. }\end{array}$ \\
\hline 2018 & $\begin{array}{l}\text { The study includes participant } \\
\text { characteristics, knowledge of pain and pain } \\
\text { management. }\end{array}$ & $\begin{array}{l}\text { Mixed-methods } \\
\text { survey }\end{array}$ & $\begin{array}{l}\text { Knowledge of care for pain and its } \\
\text { handlers showed a positive response. }\end{array}$ \\
\hline 2020 & $\begin{array}{l}\text { The intervention refers to the Staff } \\
\text { Educational Module with the aim of } \\
\text { increasing breast milk production in } \\
\text { childbirth by with Hand Expression and } \\
\text { Breast Pumps and education of mothers with } \\
\text { babies who are being treated in hospital. }\end{array}$ & $\begin{array}{l}\text { A descriptive } \\
\text { pre-/post inter- } \\
\text { vention }\end{array}$ & $\begin{array}{l}\text { The results showed that nurses were able } \\
\text { to support breastfeeding mothers in a } \\
\text { conducive atmosphere }\end{array}$ \\
\hline 2016 & $\begin{array}{l}\text { The data studied included respondent } \\
\text { demographic data and standards in family- } \\
\text { centered infant care. }\end{array}$ & $\begin{array}{l}\text { A descriptive, } \\
\text { cross-section- } \\
\text { al exploratory } \\
\text { study }\end{array}$ & $\begin{array}{l}\text { Nursing care for babies in the NICU room } \\
\text { cannot be done optimally. This is due to } \\
\text { the limited availability of the physical } \\
\text { environment, and the provision of limited } \\
\text { individual care and knowledge of nurses. }\end{array}$ \\
\hline 2019 & $\begin{array}{l}\text { The research focused on demographic } \\
\text { characteristics, nurses' knowledge about } \\
\text { developmental care and the nurses' } \\
\text { perception of the results of infant } \\
\text { developmental care. }\end{array}$ & $\begin{array}{l}\text { A cross-section- } \\
\text { al study }\end{array}$ & $\begin{array}{l}\text { The results showed that nurses obtained } \\
\text { better job satisfaction by showing better } \\
\text { performance skills in developmental care, } \\
\text { high motivation, and confidence in their } \\
\text { professional roles. }\end{array}$ \\
\hline 2018 & $\begin{array}{l}\text { Factors that impact nurses' knowledge, } \\
\text { perceptions, and practice related to } \\
\text { kangaroo care (KC) in neonatal intensive } \\
\text { care units (NICUs) in China }\end{array}$ & $\begin{array}{l}\text { A descriptive } \\
\text { cross-sectional } \\
\text { survey }\end{array}$ & $\begin{array}{l}\text { Experience in implementing } \mathrm{KC} \text { is the } \\
\text { main factor influencing the results. } \\
\text { Especially nurses with high knowledge } \\
\text { feel less obstacles during treatment }\end{array}$ \\
\hline 2015 & $\begin{array}{l}\text { The Wee Care assessment survey consists } \\
\text { of questions/observations related to } 7 \\
\text { neuroprotective core measures. }\end{array}$ & $\begin{array}{l}\text { The quality im- } \\
\text { provement proj- } \\
\text { ect study }\end{array}$ & $\begin{array}{l}\text { The results show that with appropriate } \\
\text { knowledge, training, education and } \\
\text { quality improvement opportunities, and } \\
\text { leadership skills, are factors that support } \\
\text { the development of neuroprotective } \\
\text { family-centered families to provide } \\
\text { optimal care to infants and their families. }\end{array}$ \\
\hline 2018 & $\begin{array}{l}\text { The study was conducted to measure the } \\
\text { level of integration of nurses' IDCs in their } \\
\text { daily care and to evaluate nurses' compliance } \\
\text { with IDC standards in the NICU. }\end{array}$ & $\begin{array}{l}\text { Correlational } \\
\text { study }\end{array}$ & $\begin{array}{l}\text { The results showed that there was a } \\
\text { relationship between the knowledge, } \\
\text { attitudes, and perceptions of nurses' self- } \\
\text { competence regarding infant development } \\
\text { care in the neonatal intensive care unit, } \\
\text { which led to an increase in the attitudes } \\
\text { and competencies of NICU nurses. }\end{array}$ \\
\hline
\end{tabular}

hospital policies, make it difficult for parents to be involved during treatment (Zhang et al., 2016).

\section{CONCLUSION}

Nurses' knowledge, attitudes, and perceptions of self-competence positively correlate with implementing individual developmental care in the neonatal intensive care unit. Training on developmental care and observation in its implementation is required to improve the nursing development of nurses and increase the competence of individual nurses. Positive perceptions about developmental care and organizational support are needed. The training program also provides benefits to 
Table 2. Summary of Selected Studies (Continued)

\section{The education is conducted in Japanese covering complex care of babies born with trisomy 18, and two-thirds and the collec- tion of peripheral blood in the veins and the heel.}

Non-randomized interventional study.
The results of the study showed that the neonatal special education program increased the potential of nurses to carry out care in the NICU room. In this study, there was a change in the perception of nurses' roles and their interactions with coworkers.

\begin{tabular}{|c|c|c|c|}
\hline 2017 & $\begin{array}{l}\text { Developmental care performance } \\
\text { was designed by the research team. } \\
\text { In the qualitative study, } 30 \text { experts in } \\
\text { neurodevelopmental care. The quantitative } \\
\text { study contains five domains. }\end{array}$ & $\begin{array}{l}\text { Cross-section- } \\
\text { al study with } \\
\text { mixed-method } \\
\text { study }\end{array}$ & $\begin{array}{l}\text { The total score of the quality of providing } \\
\text { growth and development care is } 74.84 \% \\
\text { with "daily routine care" having the } \\
\text { highest score }(85.67 \%) \text { and "sleep and } \\
\text { pain care" had the lowest score }(66.63 \%) \text {. } \\
\text { The total score of the structure is } 43.06 \% \text {. } \\
\text { The number of neonates treated per day } \\
\text { (B }-0.328, P=0.019 \text { ) and the number of } \\
\text { infants managed by each nurse (B }-2.543 \text {, } \\
P=0.019 \text { ) were significant variables for } \\
\text { better quality of total developmental care. }\end{array}$ \\
\hline 2017 & $\begin{array}{l}\text { There were two methods of data collection } \\
\text { used in this research. Australian neonatal } \\
\text { nurses. The questionnaire addressed } \\
\text { the demographics, age, and the number } \\
\text { of years of experience with caring for } \\
\text { extremely premature babies. In the second } \\
\text { stage, purposive sampling was used and } \\
\text { data collected through } 14 \text { semistructured } \\
\text { interviews }\end{array}$ & $\begin{array}{l}\text { A quantitative } \\
\text { and qualitative } \\
\text { study }\end{array}$ & $\begin{array}{l}\text { The results showed that neonatal nurses } \\
\text { believed that quality of life was an } \\
\text { important factor in infant development } \\
\text { but was unable to define the important } \\
\text { factors that affect quality of life in infants. }\end{array}$ \\
\hline 2016 & $\begin{array}{l}\text { A pre-and post-course questionnaire } \\
\text { evaluated both knowledge and satisfaction } \\
\text { levels regarding the course on DC and the } \\
\text { Newborn Individualized Developmental } \\
\text { Care and Assessment Program (NIDCAP). }\end{array}$ & Original article & $\begin{array}{l}\text { The results showed the average score } \\
\text { before and after the course was } 65 \% \text {, } \\
\text { respectively; } 81 \% \text { with } p=<0.001 \text {. With a } \\
\text { satisfaction score of } 4 \text { (range } 1-5 \text { ). }\end{array}$ \\
\hline
\end{tabular}

nurses; namely, it can increase self-confidence in implementing developmental care for premature babies.

\section{CONFLICT OF INTEREST}

No conflicts of interest were declared

\section{REFERENCES}

Altimier, L., Kenner, C., \& Damus, K. (2015). The Wee Care Neuroprotective NICU Program (WeeCare):TheEffect of a Comprehensive Developmental Care Training Program on Seven Neuroprotective Core Measures for Family-Centered Developmental Care of Premature Neonates. Newborn and Infant Nursing Reviews, 15(1), 6-16. https://doi.org/10.1053/j. nainr.2015.01.006

Altimier, L., \& Phillips, R. (2016). The Neonatal Integrative Developmental Care Model: Advanced Clinical Applications of the Seven Core Measures for Neuroprotective
Family-centered Developmental Care. Newborn and Infant Nursing Reviews, 16(4), 230-244. https://doi. org/10.1053/j.nainr.2016.09.030

Baghlani, R., Hosseini, M. B., Safaiyan, A., Alizadeh, M., \& Arshadi-Bostanabad, M. (2019). Neonatal intensive care unit nurses' perceptions and knowledge of newborn individualized developmental care and assessment program: A multicenter study. Iranian Journal of Nursing and Midwifery Research, 24(2), 113-117. https://doi.org/10.4103/ ijnmr.IJNMR_54_18

Blatz, M. A., Huston, A. J., \& Anthony, M. K. (2020). Influence of NICU Nurse Education on Intention to Support Lactation Using Tailored Techniques: A Pilot Study. Advances in Neonatal Care, 20(4), 314-323. https://doi.org/10.1097/ ANC.0000000000000702

Capolingua, M., \& Gill, F. J. (2018). Neonatal nurses' self-reported practices, 
knowledge and attitudes toward premature infant pain assessment and management. Journal of Neonatal Nursing, 24(4), 218-224. https://doi. org/10.1016/j.jnn.2018.03.002

Charafeddine, L., Masri, S., Sharafeddin, S. F., \& Kurdahi Badr, L. (2020). Implementing NIDCAP training in a low-middleincome country: Comparing nurses and physicians' attitudes. Early Human Development, 147(March), 105092. https://doi.org/10.1016/j. earlhumdev.2020.105092

Deng, Q., Zhang, Y., Li, Q., Wang, H., \& Xu, X. (2018). Factors that have an impact on knowledge, attitude and practice related to kangaroo care: National survey study among neonatal nurses. Journal of Clinical Nursing, 27(21-22), 4100-4111. https://doi.org/10.1111/jocn.14556

Green, J., Darbyshire, P., Adams, A., \& Jackson, D. (2017). Quality versus quantity: The complexities of quality of life determinations for neonatal nurses. Nursing Ethics, 24(7), 802-820. https:// doi.org/10.1177/0969733015625367

Kiechl-Kohlendorfer, U., Merkle, U., Deufert, D., Neubauer, V., Peglow, U. P., \& Griesmaier, E. (2015). Effect of developmental care for very premature infants on neurodevelopmental outcome at 2 years of age. Infant Behavior and Development, 39, 166-172. https://doi.org/10.1016/j. infbeh.2015.02.006

Konishi, M., Yoshioka, T., Okubo, Y., \& Kusuda, S. (2017). An exploratory intervention to expand the horizon for Japanese neonatal nurses: Acquisition and retention of knowledge and skills related to nursing practice. Journal of Neonatal Nursing, 23(5), 228-233. https://doi. org/10.1016/j.jnn.2017.03.005

Lynn Lingen, BSN, RN, R.-N. (2019). Neurodevelopmental Care.

Macho, P. (2018). Nurses' Knowledge, Attitudes, and Perceived Self-Competency Regarding Individualized Developmental Care in the Neonatal Intensive Care Unit. Nurses' Knowledge, Attitudes \& Perceived Self-Competency Regarding
Individualized Developmental Care in the Neonatal Intensive Care Unit, 1.

Mahl, S., Lee, S. K., Baker, G. R., Cronin, C. M. G., Stevens, B., Ye, X. Y., Aziz, K., Barrington, K., Clarke, M., Dunn, M., James, A., Ohlsson, A., Lee, D., Lefebvre, F., Merchant, P., Sankaran, K., Seshia, M., Singhal, N., Sorokan, T., ... Ojah, C. (2015). The Association of Organizational Culture and Quality Improvement Implementation With Neonatal Outcomes in the NICU. Journal of Pediatric Health Care, 29(5), 435-441. https://doi.org/10.1016/j. pedhc.2015.01.011

Mosqueda-Peña, R., Lora-Pablos, D., PavónMuñoz, A., Ureta-Velasco, N., MoralPumarega, M. T., \& Pallás-Alonso, C. R. (2016). Impact of a Developmental Care Training Course on the Knowledge and Satisfaction of Health Care Professionals in Neonatal Units: A Multicenter Study. Pediatrics and Neonatology, 57(2), 97-104. https://doi.org/10.1016/j. pedneo.2015.04.010

Park, J., \& Kim, J. S. (2019). Factors Influencing Developmental Care Practice Among Neonatal Intensive Care Unit Nurses. Journal of Pediatric Nursing, 47, e10-e15. https://doi.org/10.1016/j. pedn.2019.03.014

Su, Y. Y., Wang, S. H., Chou, H. C., Chen, C. Y., Hsieh, W. S., Tsao, P. N., Tsou, K. I., Hsu, C. H., Mu, S. C., Lin, H. C., Huang, C. C., \& Hsieh, K. S. (2016). Morbidity and mortality of very low birth weight infants in Taiwan-Changes in 15 years: A population based study. Journal of the Formosan Medical Association, 115(12), 1039-1045. https://doi.org/10.1016/j. jfma.2016.10.011

WHO. (2012). Born too soon. The Global Action Report on Preterm Birth.

Zhang, X., Lee, S. Y., Chen, J., \& Liu, H. (2016). Factors Influencing Implementation of Developmental Care Among NICU Nurses in China. Clinical Nursing Research, 25(3), 238-253. https://doi. org/10.1177/1054773814547229 